\title{
Numerical modeling of a gravity-driven instability of a cold hanging glacier: reanalysis of the 1895 break-off of Altelsgletscher, Switzerland
}

\author{
Jérome FAILLETTAZ, ${ }^{1}$ Didier SORNETTE, ${ }^{2,3,4}$ Martin FUNK ${ }^{1}$ \\ ${ }^{1}$ Laboratory of Hydraulics, Hydrology and Glaciology (VAW), ETH-Zürich, CH-8092 Zürich, Switzerland \\ E-mail: faillettaz@vaw.baug.ethz.ch \\ ${ }^{2}$ Department of Management, Technology and Economics, ETH-Zürich, CH-8092 Zürich, Switzerland \\ ${ }^{3}$ Department of Earth Sciences, ETH-Zürich, CH-8092 Zürich, Switzerland \\ ${ }^{4}$ Institute of Geophysics and Planetary Physics, University of California, Los Angeles, Los Angeles,
} California 90095-1567, USA

\begin{abstract}
The Altels hanging glacier in Switzerland broke off on 11 September 1895. The ice volume of this catastrophic rupture was estimated as $4 \times 10^{6} \mathrm{~m}^{3}$, the largest icefall event ever observed in the Alps. However, the causes of this collapse are not entirely clear. Based on previous studies, we reanalyzed this break-off event, with the help of a new numerical model, initially developed by Faillettaz and others (2010) for gravity-driven instabilities. The simulations indicate that a break-off event is only possible when the basal friction at the bedrock is reduced in a restricted area, possibly induced by the storage of infiltrated water within the glacier. Further, our simulations reveal a two-step behavior: (1) a first quiescent phase, without visible changes, with a duration depending on the rate of change in basal friction; (2) an active phase with a rapid increase of basal motion over a few days. The general lesson obtained from the comparison between the simulations and available observations is that detectable precursors (crevasse formation and velocity increase) of the destabilization process of a hanging glacier, resulting from a progressive warming of the ice/bed interface towards a temperate regime, will appear only a few days prior to the break-off.
\end{abstract}

\section{INTRODUCTION}

Icefalls pose a considerable risk to humans, settlements and infrastructures. Their destructive power is usually greater in winter, as they can drag snow and ice in their wake. In the Alps one of the most tragic icefall events occurred in 1965 in Switzerland, when a major part of Allalingletscher broke off and killed 88 employees of the Mattmark dam construction site (Röthlisberger, 1981; Raymond and others, 2003). Following this event, interest in the instability of hanging glaciers grew within the alpine glaciological community. In 1973, the first successful icefall prediction was performed by Flotron (1977) and Röthlisberger (1981) at the Weisshorn hanging glacier, which regularly poses a threat to the village of Randa, in Valais, Switzerland. Due to climatic variations, some hanging glaciers undergo rapid changes, leading either to isolated catastrophic events or to new situations with no historical precedent. It is difficult to perform direct measurements on these steep, heavily crevassed and avalanche-endangered glaciers. Measurements are often sparse and fragmentary, and therefore difficult to interpret. They have always been performed after clear signs of destabilization, so the conditions prevailing before an unstable state are unknown. The factors responsible for the destabilization of large ice masses are the strength of the ice and the stresses in the zone of fracture. However, the physics of the ice fracture and the feedback mechanisms between crevassing, ice deformation and load distribution are complex and mostly unknown. Lack of theory and sparse measurements make an accurate stability assessment difficult.

To cope with these difficulties, we developed a numerical model describing the progressive maturation of a mass towards a gravity-driven instability, which combines basal sliding and cracking (described by Faillettaz and others, 2010). Our primary hypothesis was that gravity-driven ruptures in natural heterogeneous material are characterized by a common triggering mechanism resulting from the competition between frictional sliding and tension cracking.

The present paper is devoted to the application of this general numerical model to a particular gravity-driven instability: the breaking-off of hanging glaciers. The gigantic breaking-off of the Altels hanging glacier is an interesting case for several reasons:

It is the largest break-off recorded in the Alps.

It was well documented by Forel (1895), Heim (1895) and Du Pasquier (1896), within the limits of their knowledge - their observations relate to the rupture of the glacier and include photographs of the glacier before and after the collapse.

The causes of this glacier instability are not entirely understood, despite the reanalysis of Röthlisberger (1981) using data collected by Forel (1895), Heim (1895) and Du Pasquier (1896). However, it is suspected that hot summers prior to the event triggered the break-off.

It is the only well-documented break-off of a cold hanging glacier where progressive warming of the ice/bed interface towards temperate conditions has likely driven the phenomenon.

Any break-off of this size is of interest in the context of global climate change.

Our study should improve the understanding of the processes leading to this catastrophic phenomenon. Moreover, 


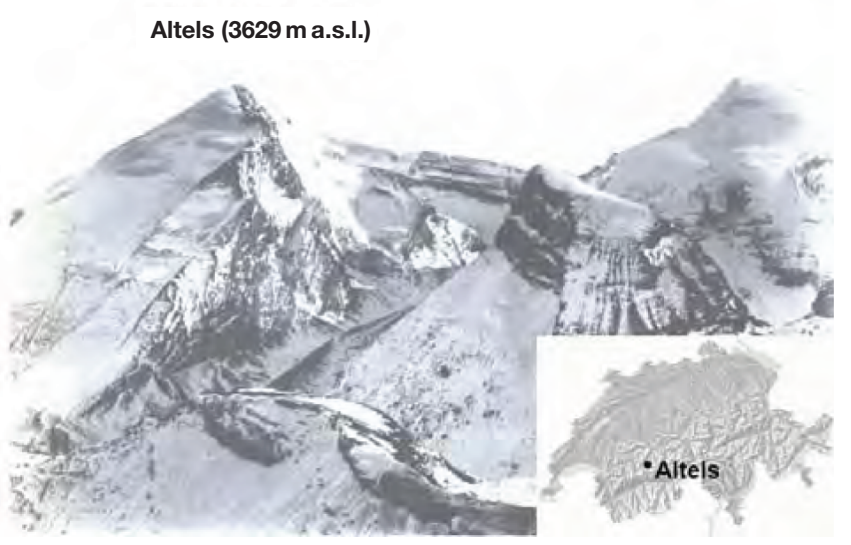

Fig. 1. Overview of Altelsgletscher, 25 November 1894, 10 months before the glacier broke off. (Photograph: P. Montandon from Englistliggrat, 2665 m a.s.I.)

it should give new insights into the probable causes of this particular gravity-driven instability and reveal precursors of this event. Section 2 describes the study site and gives a qualitative description of the rupture. Section 3 describes how the model is implemented, and the main qualitative and quantitative results are presented in section 4 .

\section{STUDY SITE: ALTELS}

\subsection{Generality and description of the event}

The Altels (Berner Oberland, Switzerland) summit is $3629 \mathrm{~m}$ a.s.l. and has a pyramidal shape. The northwestern flank is $1500 \mathrm{~m}$ high with a $35-40^{\circ}$ slope (Fig. 1). It consists of relatively smooth malm limestone (see Fig. 3). In the mid-19th century, this face was largely covered with an unbalanced ramp glacier (i.e. the snow accumulation is mostly compensated by break-off; Pralong and Funk, 2006), located between 3629 and $3000 \mathrm{~m}$ a.s.I. In the early morning of 11 September 1895, a large part of the glacier broke off and tumbled down. This icefall lasted $\sim 1 \mathrm{~min}$ and the accompanying thunder could be heard in Kandersteg
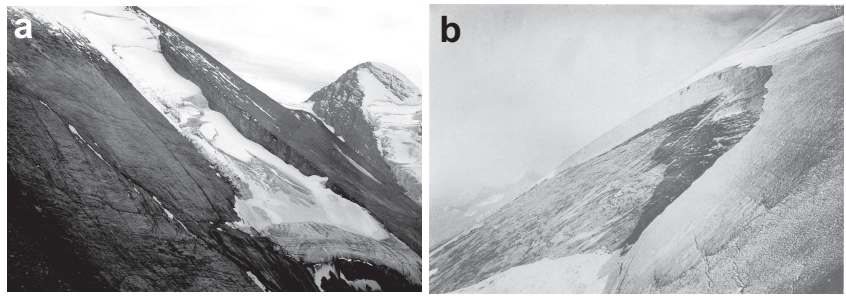

Fig. 3. (a) Side glacier remaining in 1979. Bedrock consists of malm limestone. (Photograph: H. Röthlisberger.) (b) Side view of the bedrock after the 1895 break-off (Heim, 1895).

( $\sim 10 \mathrm{~km}$ away). Many people thought it was an earthquake. This catastrophic break-off was carefully described and reported by Forel (1895), Heim (1895) and Du Pasquier (1896) and, later, by Röthlisberger (1981).

The volume of the break-off was estimated as $4 \times 10^{6} \mathrm{~m}^{3}$, which is the largest known glacial fall in the Alps. The resulting ice avalanche ravaged the high mountain pasture situated underneath (the Spittelmatte) and killed six people and 170 cattle. Due to its high velocity $\left(430 \mathrm{~km} \mathrm{~h}^{-1}\right.$ (Heim, 1895; Röthlisberger, 1981)), the avalanche piled up to $300 \mathrm{~m}$ on the opposite slope, towards the Üschinengrat (Fig. 2). An area of $\sim 1 \mathrm{~km}^{2}$ of the pasture was buried under an ice layer 3-5 $\mathrm{m}$ thick. As Forel (1895) reported, a similar event had occurred at the same place in 1782, killing four people and hundreds of domestic animals (Raymond and others, 2003). Forel (1895) pointed out that the 1895 summer was warmer than usual. The event is unlikely to occur again, because Altelsgletscher has almost disappeared (a tongue remains on its left side, which will melt away in the near future; Fig. 3a).

\subsection{Rupture and probable causes}

The crown crack was a huge regular parabolic-like arch with a width of $\sim 580 \mathrm{~m}$ (Figs $3 \mathrm{~b}$ and $4 \mathrm{~b}$ ). The ice thickness was $\sim 40 \mathrm{~m}$ at the crown crack and $20 \mathrm{~m}$ at the glacier terminus (Fig. 3b). The final rupture took place and propagated along the bedrock.

Forel (1895) analyzed the causes of the rupture. He suggested the extremely hot previous summers may have

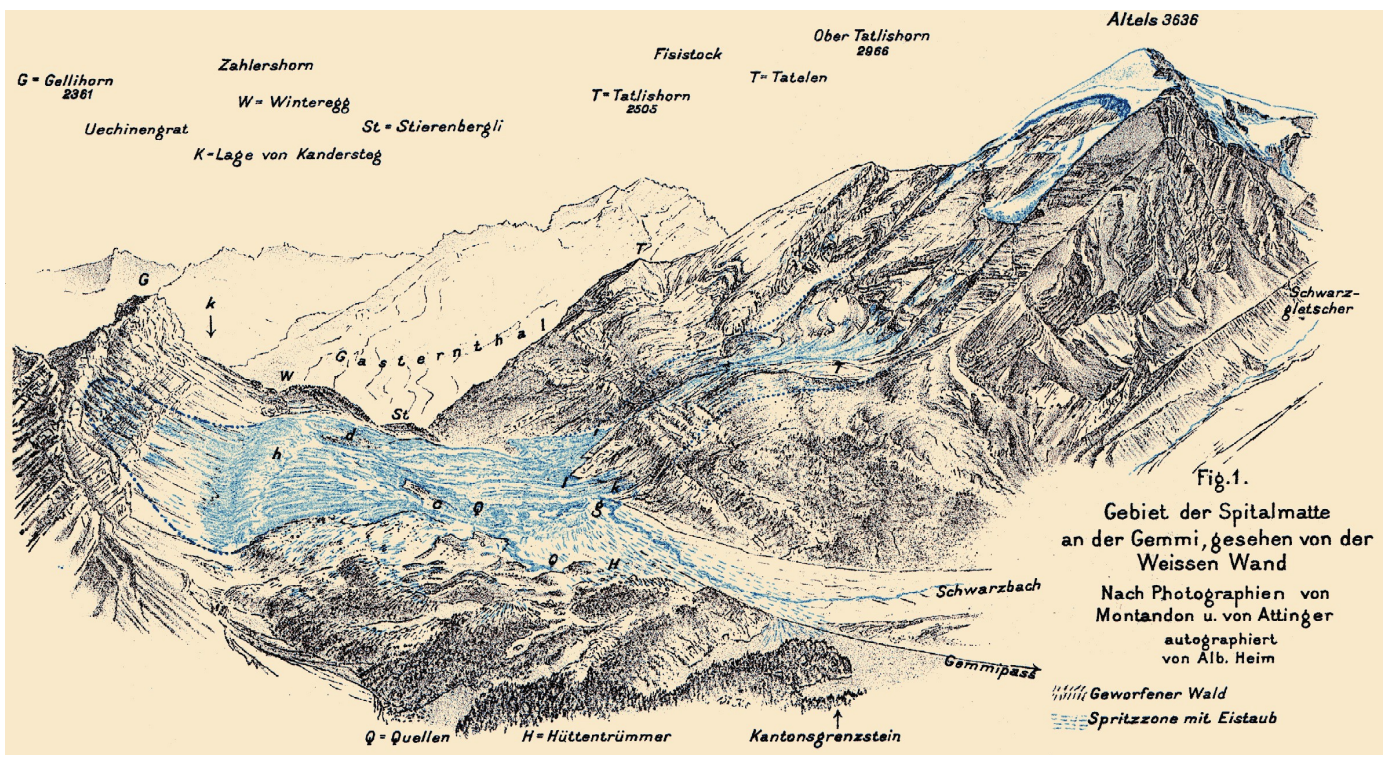

Fig. 2. General overview of the event (after Heim, 1895). 


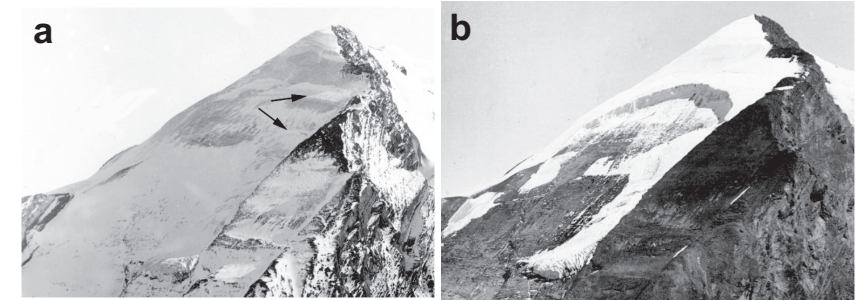

Fig. 4. Altelsgletscher (a) before and (b) after its break-off. (Photograph: P. Montandon, 25 November 1894 and 15 September 1895; Archiv des Alpinen Museums Bern.) Black arrows in (a) indicate opened crevasses on the side glacier

been linked to this event. This could explain why the glacier was no longer mostly frozen at the bed and lost adhesion, due to a thin film of water between the bedrock and the ice.

Röthlisberger (1981) reanalyzed the documented field observations of Forel (1895), Heim (1895) and Du Pasquier (1896) to infer the thermal conditions of Altelsgletscher before its break-off (Fig. 5). On the basis of Figures $3 \mathrm{~b}$ and 4b, Röthlisberger (1981) concluded that: (1) The central part of the glacier was temperate, as the bedrock was completely ice-free in this area after the break-off. This is an indication that the glacier could slip off in this area. Therefore the glacier was not frozen to the bedrock there. (2) Above the bergschrund, the glacier was frozen to its bedrock, as well as at the margins near the terminus, where some remaining ice (likely still frozen to the bedrock) can be recognized (white spots). He argued that the glacier geometry is likely to explain such thermal conditions at the bedrock. In the central part, a large snow-covered zone can be recognized. In this moderately steep area, surface meltwater could percolate into the cold glacier and refreeze. The release of latent energy leads to an increase in englacial temperatures. If this process is strong enough, it could explain why the glacier bed became temperate in this part. The margins (above the bergschrund and near the terminus) are much steeper and mostly snow-free, so meltwater can hardly penetrate into the glacier and there is no warming by release of latent energy.

Röthlisberger (1981) analyzed the retaining forces of the hanging glacier and the possible causes of the break-off. He found:

Adhesion to the bedrock: Given the dimensions of the unstable ice slab compared to its thickness, the basal properties should be crucial to the stability. The existence of temperate conditions at the bedrock/glacier interface is a destabilizing process that favors sliding of the glacier on its bed. When the glacier slides over bumps or bedrock asperities, cavities form above the bedrock, leading to a loss of adhesion between the glacier and the bedrock. Moreover, surface melting and high water pressure at the interface favor and accelerate the enlargement of the cavities. This could lead to destabilization of the glacier in a very short time (from 1 day to 1 week). Precursors of such a destabilization process are hardly detectable, as the presence of such cavities cannot be easily determined from the surface.

Southern support of the side glacier: The side glacier could also be important to the global stability of the hanging glacier. In Figure $4 \mathrm{a}$ it is possible to distinguish opened crevasses on the side glacier prolongated into Altelsgletscher 10 months before the rupture. These

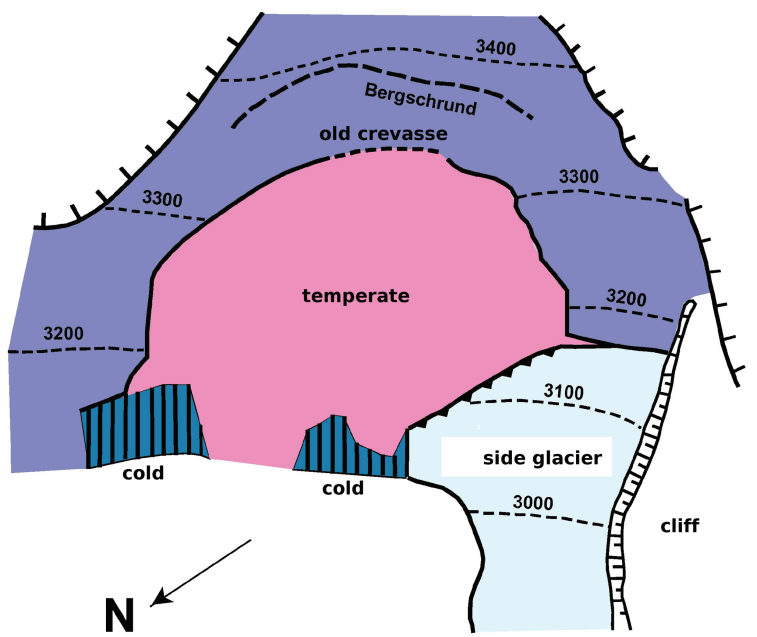

Fig. 5. Schema of the supposed thermal conditions at the bedrock and in the glacier before its break-off (after Röthlisberger, 1981).

crevasses could have formed because of sliding of the side glacier, which acts as a support for the whole glacier. Such a sliding phenomenon was observed in 1895 and again in $1927 / 28$, when the sliding speed was $25-30 \mathrm{ma}^{-1}$ (Röthlisberger, 1981).

Support of the frozen margins: It is possible that the lateral support of the frozen margins played a considerable part in the stability of the glacier, especially because of the significant surface melting of the glacier 2 years before the rupture (from a photograph by Du Pasquier, 1896). Heim (1895) and Du Pasquier (1896) analyzed air temperature data from different locations in Switzerland and found that the 1895 summer was exceptionally warm. With the prevailing climate conditions, sufficient meltwater could have been produced to weaken the basal frozen support.

Traction at the crown crack (cohesion): The crown crack was already open, to a limited depth, 10 months before the rupture (Fig. 4a), indicating large tensile stresses.

\subsection{Temperature and precipitation before $\mathbf{1 8 9 5}$}

As Forel (1895), Heim (1895) and Röthlisberger (1981) pointed out, very warm summers (generating much more meltwater than usual) are suspected to have favored the instability, so we investigated the evolution of climatic conditions at Altelsgletscher before its 1895 break-off. A database with homogenized continuous daily time series of temperature and precipitation since 1865 is available at the Federal Office of Meteorology and Climatology MeteoSwiss. The time series are corrected for systematic biases (e.g. due to the relocation of weather stations or changing measurement techniques (Begert and others, 2005)). A total of 12 MeteoSwiss stations are available; we used the two closest stations, one located in Sion (35 km southwest) and the other in Bern (60 km north).

Air temperature is known to be relatively well correlated over large distances (Begert and others, 2005) and can therefore be extrapolated with confidence. We evaluated the temperature at $3000 \mathrm{~m}$ a.s.l. by applying a temperature gradient of $-6^{\circ} \mathrm{C} \mathrm{km}^{-1}$ per $1000 \mathrm{~m}$ on the daily mean values from the two meteorological stations. The extrapolation of solid precipitation is more problematic. As a first approximation, we computed the mean precipitation from 


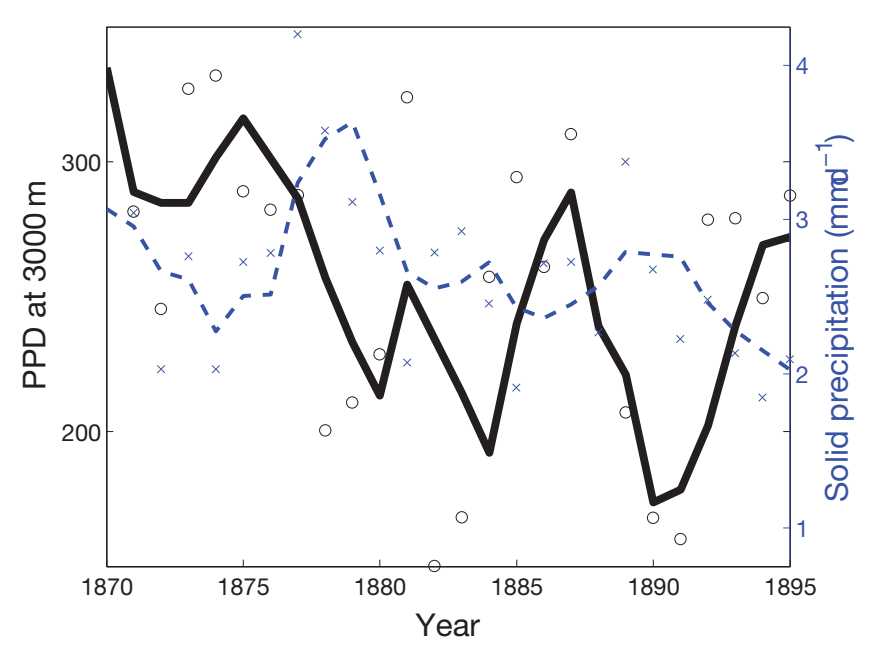

Fig. 6. Three-year running mean of positive degree-days (solid black curve) and solid precipitation (dashed curve) between 1870 and 1895 at $3000 \mathrm{~m}$ a.s.l. at the location of the 1895 Altels break-off. Annual values are also indicated (circles for PDD and crosses for solid precipitation).

the two stations and considered it to be solid when the extrapolated temperature at $3000 \mathrm{~m}$ was $<0^{\circ} \mathrm{C}$.

Daily snow and ice melt rates can be assumed proportional to the positive degree-day (PDD) (Hock, 2003). Because the albedo of ice is lower than that of snow, the melting rate will be higher after the annual snow cover has disappeared. Total solid precipitation and the sum of the PDDs are indications of the annual mass balance of the glacier, i.e. low annual solid precipitation rates will lead to an earlier disappearance of the snow cover and therefore to higher melt rates, because of a longer time with low albedo.

Time series of PDDs since 1870 (Fig. 6) indicate higher values in the 1870 s and an increasing trend over the 5 years before 1895. Moreover, solid precipitation decreased during this period, indicating less snow accumulation. Five years before the break-off, the glacier experienced smaller annual mass balances (decrease of solid precipitation combined with a larger PDD). These results are compatible with the descriptions of Heim (1895) and Röthlisberger (1981).

\section{NUMERICAL MODELING}

The aim of the present work is to reanalyze this event by applying a new numerical model designed for describing natural gravity-driven instabilities (Faillettaz and others, 2010). This model allows us to test the different hypotheses proposed to explain the break-off of Altelsgletscher.

\subsection{Model description}

We use a model describing the progressive maturation of a mass towards a gravity-driven instability, which combines basal sliding and cracking. Our hypothesis is that gravitydriven ruptures in natural heterogeneous materials are characterized by a common triggering mechanism, resulting from the competition between frictional sliding and tension cracking. Heterogeneity of material properties and dynamical interaction of damage and cracks along the sliding layer seem to have a significant influence on the global behavior.

This numerical model is based on the discretization of the natural medium in terms of blocks and springs forming

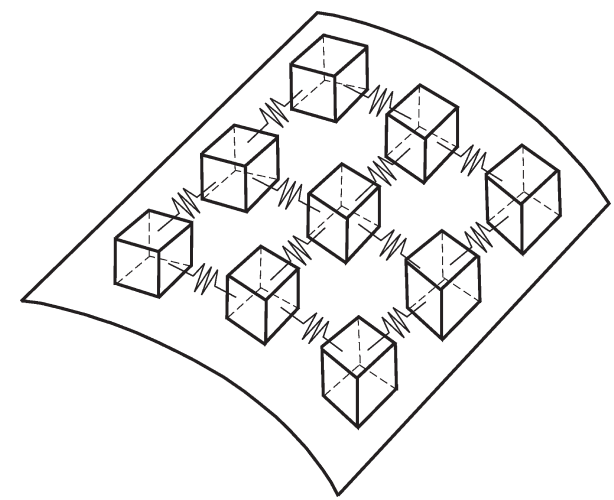

Fig. 7. Illustration of the model consisting of springs and blocks resting on an inclined plane. The blocks lie on an inclined curved surface and gravity is the driving force. Only a small subset of the spring-block system is shown here.

a two-dimensional network sliding on an inclined plane. Each block, which can slide, is connected to its four neighbors by springs that can fail, depending on the history of displacement and damage. We develop physically realistic models describing the frictional sliding of the blocks on the supporting surface, and the tensile failure of the springs between blocks acts as a proxy for crack opening. Frictional sliding is modeled with a state- and velocity-weakening friction law with a threshold. This means that solid friction is not used as a parameter but as a process evolving with the concentration of deformation and properties of sliding interfaces. Crack formation is modeled with a timedependent cumulative-damage law with thermal activation, including stress corrosion. In order to reproduce cracking and dynamical effects, all equations of motion (including inertia) for each block are solved simultaneously.

This model improves the multi-block model of Andersen and others (1997) and Leung and Andersen (1997) in two ways. First, we use the state- and velocity-weakening friction law instead of a constant (or just state- or velocityweakening) solid friction coefficient. Second, rather than a static threshold for spring failures, we model the progressive damage accumulation via stress corrosion and other thermally activated processes aided by stress. Both improvements make the numerical simulations significantly longer, but have the advantage of embodying, rather well, the known empirical phenomenology of sliding and damage processes. Adding the state- and velocity-dependent friction law and time-dependent damage processes allows us to model the interplay between sliding and cracking between blocks and the overall self-organizing of the system of blocks (Faillettaz and others, 2010).

The geometry of the system of blocks interacting via springs and with a basal surface is shown in Figure 7. In summary, the model includes the following characteristics:

Frictional sliding on the ground.

Heterogeneity of basal properties.

Possible tension rupture by accumulation of damage.

Dynamical interactions between cracks or damage along the sliding layer.

Geometry and boundary conditions.

Interplay between frictional sliding and cracking. 


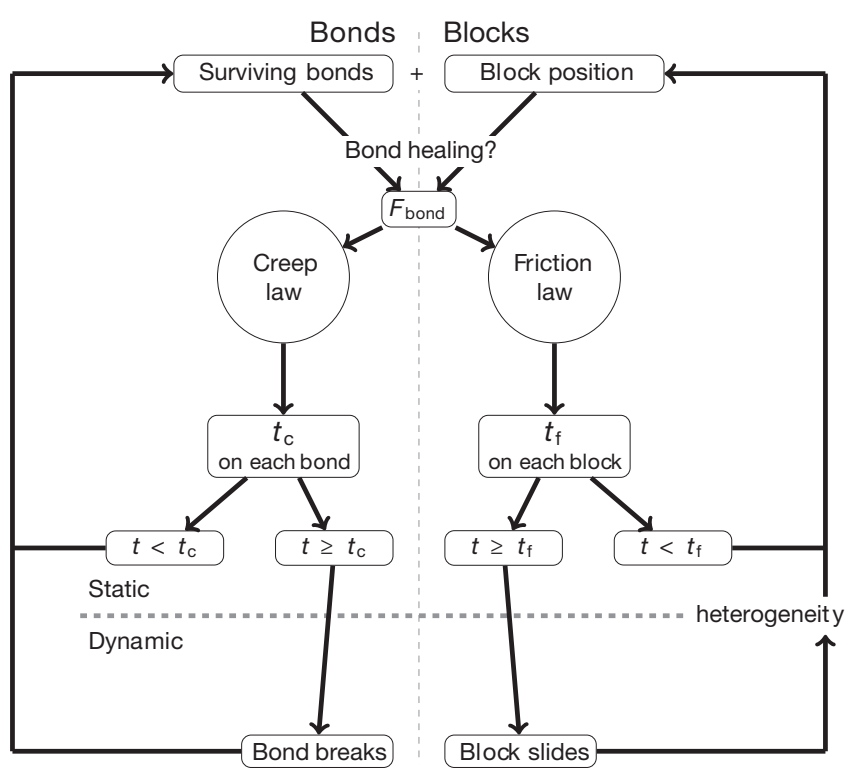

Fig. 8. Flow-chart of the modified spring-block model.

The steps describing how the development of the instability is modeled are shown in Figure 8. As explained above, two phases have to be distinguished:

A quasi-static (quiescent) phase corresponding to the nucleation of block sliding and bond rupture.

A dynamical (active) phase corresponding to the sliding phase of the blocks and the failure of the bonds.

\subsection{Geometric parameters}

We first have to consider the geometric input parameters for modeling the Altelsgletscher. The glacier is discretized into a system of regular cubic blocks. The application of this model to the time evolution of an unstable glacier implies that snow accumulation at the surface of the glacier is neglected, corresponding to a timescale of 1-2 years. This assumption seems to be justified for Altelsgletscher, as its northwestern face has a steep slope $\left(35-40^{\circ}\right)$ and is subjected to strong winds, drifting snow away. In addition, typical snow and ice accumulation rates are low compared with the overall thickness $(\sim 30 \mathrm{~m})$ of the glacier.

In order to obtain a realistic description of the damage and fragmentation process that may develop in the ice mass, we need a sufficient number of blocks. As a compromise between reasonable sampling and numerical speed, we use a model composed of $70 \times 70$ blocks for this example. It is possible to evaluate the size of the unstable part from analysis of Figure 4 and from direct observations. Accordingly, the glacier surface area was chosen to be $\sim 4 \mathrm{~km}^{2}$, with a mean ice depth of $30 \mathrm{~m}$. As we consider a model composed of $70 \times 70$ blocks, each block corresponds to a discrete mesh $30 \mathrm{~m}$ thick, $30 \mathrm{~m}$ long and $30 \mathrm{~m}$ wide. The weight of each block is $\sim 24.75 \times 10^{6} \mathrm{~kg}$ (density $917 \mathrm{~kg} \mathrm{~m}^{-3}$ ).

The slope of the bedrock, $\phi$, ranges from $35^{\circ}$ (lower part) to $40^{\circ}$ (upper part) (Fig. 9). To account for the curvature of the bedrock slope, we used a digital elevation model (DEM) supporting the blocks described above (Fig. 10).

We now describe the two key processes in the model, the friction and damage laws, applied to blocks and bonds, respectively.

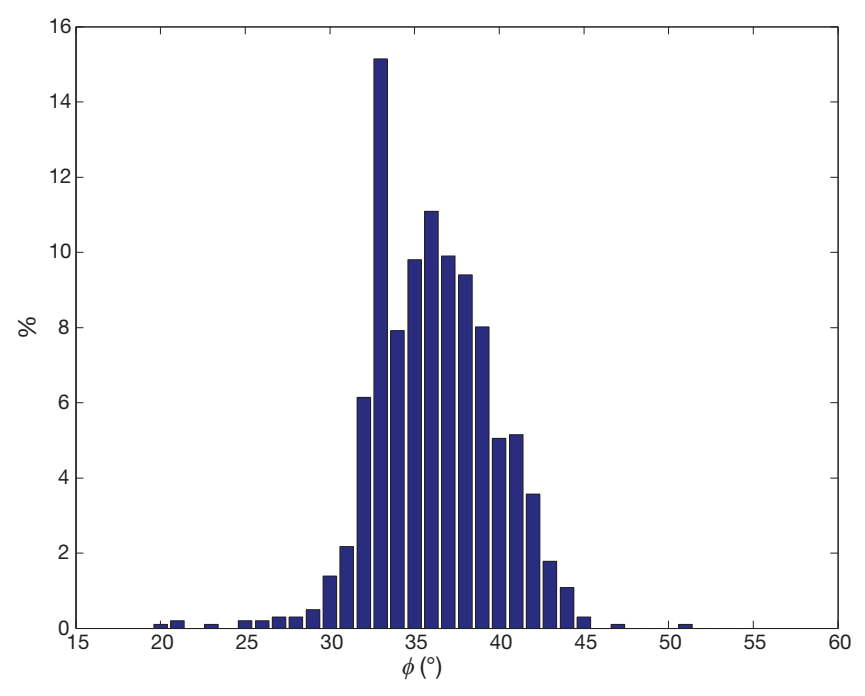

Fig. 9. Distribution of the slope of the bedrock at the position of the blocks.

\subsection{Friction law between the discrete blocks and the basal surface}

Figure 3 and the discussion in section 2.2 suggest that the central part of the glacier was temperate at the time of its destabilization. The rupture developed and propagated within the ice (on the margin) as well as above the bedrock (central part). These two zones need to be considered here, depending on where the modeled discrete ice blocks lie (either on ice or on the bedrock). The friction law between the discrete blocks and the basal surface should also capture both cases, ice/ice friction and ice/bedrock friction. Guided by the rate and state friction character of rock (Dieterich, 1994) and ice (Fortt and Schulson, 2009; Lishman and others, 2011), a rate- and state-dependent friction law seems to be adequate to describe both ice/ice friction and ice/bedrock friction. The version of the rate/state-variable constitutive law, currently most accepted as being in reasonable agreement with experimental data on solid friction, is known as the Dieterich-Ruina law (Dieterich, 1994):

$$
\mu(\dot{\delta}, \theta)=\mu_{0}+A \ln \frac{\dot{\delta}}{\dot{\delta}_{0}}+B \ln \frac{\theta}{\theta_{0}},
$$

where the state variable, $\theta$, is usually interpreted as proportional to the surface of contact between asperities of

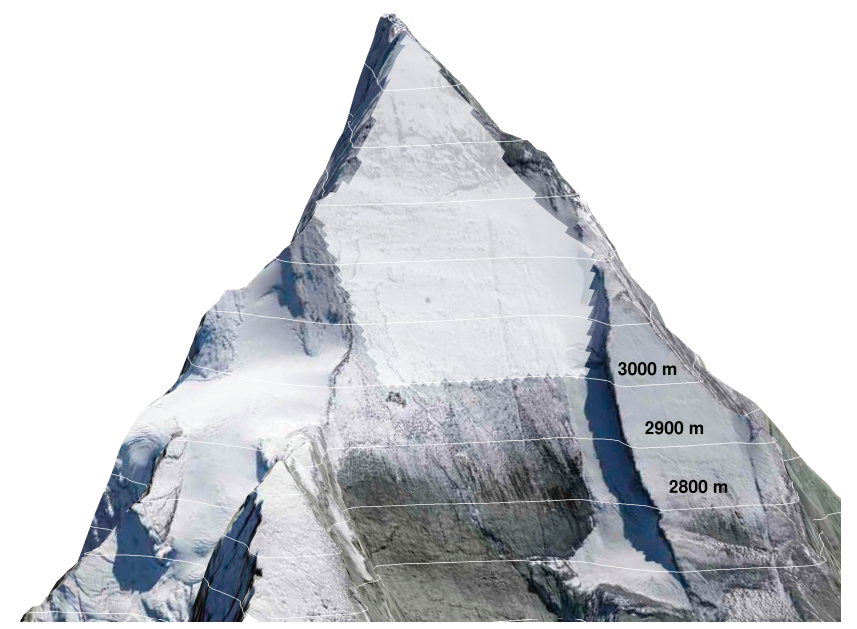

Fig. 10. DEM of the Altels. 
the two surfaces. The constant $\mu_{0}$ is the friction coefficient for a sliding velocity $\dot{\delta}_{0}$ and a state variable $\theta_{0} . A$ and $B$ are coefficients that depend on material properties.

The time evolution of the state variable, $\theta$, is described by

$$
\frac{\mathrm{d} \theta}{\mathrm{d} t}=1-\frac{\theta \dot{\delta}}{D_{\mathrm{c}}}
$$

where $D_{\mathrm{c}}$ is a characteristic slip distance, usually interpreted as the typical size of asperities. The friction law, Equation (1), with Equation (2), accounts for the fundamental properties of a broad range of surfaces in contact, namely that they strengthen (age) logarithmically when ageing at rest, and tend to weaken (rejuvenate) when sliding.

The primary parameter that determines stability, $A-B$, is a material property. Physically, $A-B$ indicates the sensitivity of the friction coefficient to velocity change: a negative value indicates velocity-weakening leading to an unstable slip; a positive value indicates velocity-strengthening leading to a stable slip. Faillettaz and others (2010) showed that the case $A=B$ is of special interest because it retrieves the main qualitative features of the two classes, and also because, empirically, $A$ is very close to $B$. Assuming $A=B$ is therefore reasonable and ensures more robust results. The critical time, $t_{\mathrm{f}}$, signaling the transition from subcritical sliding to dynamical inertial sliding is given in this case (Faillettaz and others, 2010) by

$$
t_{\mathrm{f}}=\frac{\theta_{0}}{\exp \left(\frac{\mu-\mu_{0}}{A}\right)-1},
$$

for $\mu>\mu_{0}$. (Details of how this equation is obtained are given in the Appendix.) Note that $t_{f} \rightarrow \infty$ for $\mu \leq \mu_{0}$, where $t_{\mathrm{f}}$ is the time when the block starts sliding, $\mu_{0}$ is a constant friction coefficient, $A$ is a constant parameter depending on material properties and $\theta_{0}$ is the state parameter at steady state. The parameter $\mu$ is evaluated for each block with the definition of the solid friction, $\mu=T / N$, where $T$ is the tangential force determined from the positions of its connected neighbors and $N$ is the normal component of the weight of the block. The state parameter, $\theta_{0}$ in Equation (3), is given by (see Appendix)

$$
\theta_{0}=\frac{D_{\mathrm{c}}}{\dot{\delta}_{0}}
$$

where $\dot{\delta_{0}}$ is generally interpreted as the initial low velocity of a sliding mass, before it starts to accelerate towards its dynamical instability and where $D_{c}$ can be interpreted as a characteristic slip distance over which different asperities come in contact.

Three parameters have to be correctly evaluated to model the frictional processes within the glacier: $\mu_{0}, A$ and $\theta_{0}$. An increasing friction coefficient with increasing sliding velocity (velocity-strengthening) at low velocities has been observed for polished ice-on-ice (Kennedy and others, 2000; Montagnat and Schulson, 2003), ice-on-granite (Barnes and others, 1971) and ice-on-ice along a Coulombic fault (Fortt and Schulson, 2009). A decreasing friction coefficient with increasing sliding velocity (velocity-weakening) at high velocities has also been observed (Barnes and others, 1971; Kennedy and others, 2000). The transition between these two regimes occurs at a velocity of $10^{-5} \mathrm{~m} \mathrm{~s}^{-1}$ (Fortt and Schulson, 2009). These two different behaviors are generally explained by two physical mechanisms, depending on the sliding velocity regimes:
The first mechanism is the water-lubrication mechanism (produced by frictional heat at the sliding surface) working at sliding velocities above $\sim 0.01 \mathrm{~m} \mathrm{~s}^{-1}$. The water-lubrication mechanism is characterized by the low viscous resistance of a water film produced by frictional heat at the sliding interface (Barnes and others, 1971; Kennedy and others, 2000; Montagnat and Schulson, 2003; Maeno and Arakawa, 2004).

The second mechanism is the adhesion and plastic deformation of ice at the friction interface, which is present at velocities below $\sim 0.01 \mathrm{~m} \mathrm{~s}^{-1}$ (Kennedy and others, 2000; Montagnat and Schulson, 2003; Maeno and Arakawa, 2004).

By analogy with rock physics, a rate- and state-dependent friction model for fresh and sea ice was proposed recently (Fortt and Schulson, 2009; Lishman and others, 2011). Such a model enables us to explain the change in the friction coefficient when varying sliding velocity along Coulombic shear faults or slip histories. The experiments performed by Fortt and Schulson (2009) at $-10^{\circ} \mathrm{C}$ on sliding along Coulombic shear faults in ice suggest that the ice/ice friction coefficient is velocity-dependent and varies between 0.6 and 1.4 , depending on the applied sliding velocity along the fault. As these last results are the closest to our case, we used a mean value of $\mu_{0}^{\text {ice/ice }}=1$ in our calculation.

Once the block slides, the dynamics is controlled by a kinetic friction coefficient, which is in general smaller than the static coefficient, $\mu_{0}^{\text {ice/ice }}$. At low temperatures, Kennedy and others (2000) and Fortt and Schulson (2009) found a relatively constant friction coefficient around 0.6 for sliding velocities less than $10^{-4} \mathrm{~ms}^{-1}$, and rapidly decreasing values down to 0.1 at velocities more than $10^{-4} \mathrm{~m} \mathrm{~s}^{-1}$. As velocities more than $10^{-4} \mathrm{~m} \mathrm{~s}^{-1}$ are not expected in our model describing the nucleation phase of the catastrophic rupture, we assume a kinetic friction coefficient, $\mu_{\mathrm{d}}=0.6$.

Next, we turn to the evaluation of coefficient $A$ (and $B$, since we have made the simplifying assumption that $B=A$ ) in the rate- and state-dependent friction law (Equation (1)). Laboratory experiments suggest that $A$ is smaller than $\mu_{0}$ by typically one and sometimes up to two orders of magnitude for rock (Scholz, 1998, 2002; Ohmura and Kawamura, 2007), ranging from 0.01 to 0.2 . A recent experiment on saline ice suggests that $A$ could be significantly higher for ice $(A \approx 0.3$; Lishman and others, 2011). As we do not have access to strong experimental constraints and since the friction law should be valid for both ice/ice and ice/bedrock friction, we choose $A \approx 0.1$, corresponding to one-tenth of the static friction coefficient, which is the upper limit given by Ohmura and Kawamura (2007) for rock. This choice seems reasonable for both cases.

The last parameter to be determined is $\theta_{0}$ in Equation (4). In the case of a glacier, the sliding velocity is typically of the order of centimeters per day. Therefore a roughly correct estimate is $\dot{\delta_{0}} \approx 1 \mathrm{~cm} \mathrm{~d}^{-1}$. $D_{\mathrm{c}}$ can be interpreted as a characteristic slip distance over which different asperities come in contact. It is difficult to decide this value. Recent seismological literature reports that $D_{c}$ lies in the range of tens of centimeters to meters for earthquakes (Mikumo and others, 2003; Zhang and others, 2003). We arbitrarily choose $D_{\mathrm{c}} \simeq 1 \mathrm{~m}$. Inserting this value in Equation (4), we obtain $\theta_{0}=100$ days.

To account for the heterogeneity and roughness of the sliding surface, the state variable $\theta_{\mathrm{i}}$ is reset to a new random 
value once the dynamical sliding stops. This random value should not be chosen too low, so a block which just stopped sliding does not switch immediately into a new dynamical phase (i.e. $t_{\mathrm{f}}=0$ ). Thus, we assign $\theta_{\mathrm{i}}=\nu \theta_{0}$, with $\nu$ uniformly distributed between 0.5 and 1.5.

Finally, the possible water lubrication of the bedrock leading to a progressive decrease of the ice/rock frictional resistance is modeled using a progressive decrease of the friction coefficient, $\mu_{0}$, at the interface between the simulated ice block and the basal surface. In this way, we account for the progressive onset of the temperate central zone by changing only one parameter.

\subsection{Creep law}

As discussed in section 3.1, bonds are modeled as linear springs in parallel with an Eyring dashpot. The springs transmit the forces associated with the relative displacements of the blocks. The spring stiffness has also to be evaluated in order to reflect the elastic property of the bulk ice mass. In continuous elasticity, Hooke's law of elasticity relates stress, $\sigma$, and strain, $\epsilon$, via Young's modulus, $E: \sigma=E \epsilon$. This leads to the expression: $\sigma_{\text {bulk }}=E_{\text {ice }}(\delta L / L)$. This stress is applied to a side surface of the block, $S=H L$ (where $H$ is the height and $L$ the length of the surface), leading to an equivalent force in the bulk, $F_{\text {bulk }}=E_{\text {ice }}(\delta L / L) S$. A linear spring is subjected to forces given by $F_{\text {bond }}=K_{\text {bond }} \delta L$. In order to find an equivalent behavior, these two forces have to be of the same order, leading to a spring stiffness given by $K_{\text {bond }}=E_{\text {ice }} H$. Usually values for $E_{\text {ice }}$ are reported to be 9 GPa (Petrenko and Whitworth, 1999; Petrovich, 2003). However, there is a disagreement of an order of magnitude between measurements of $E$ in the laboratory $(9 \mathrm{GPa})$ and field observations ( 1 GPa), as argued by Vaughan (1995).

Depending on the applied stress, ice has either linear viscous or nonlinear viscous behavior. In glaciers, ice creep is usually described by a nonlinear viscous rheology, called Glen's flow law (Hutter, 1983, and references therein). This law relates strain rate and stress in the secondary creep regime under steady-state conditions. It is thus not possible to use this law to describe tertiary creep and the rupture of a bond. However, Hutter (1983) states that the so-called Prandtl-Eyring flow model shows behavior compatible with Glen's flow law at low stresses. Nonlinear viscous behavior is introduced in our model with an Eyring dashpot in parallel with a linear spring of stiffness, $K_{\text {bond }}$ (which is analogous to the Prandtl-Eyring flow model), following Nechad and others (2005). Its deformation, $e$, is governed by the Eyring dashpot dynamics:

$$
\frac{\mathrm{d} e}{\mathrm{~d} t}=K \sinh \left(\beta s_{\text {dashpot }}\right),
$$

where the stress in the dashpot, $s_{\text {dashpot, }}$ is given by

$$
s_{\text {dashpot }}=\frac{s}{1-P(e)}-E e \text {. }
$$

Here $s$ is the total stress applied to the bond and $P(e)$ is the damage accumulated within the bond during its history leading to a cumulative deformation, e. $P(e)$ can be equivalently interpreted as the fraction of representative elements within the bond which have broken, so the applied stress, $s$, is supported by the fraction, $1-P(e)$, of unbroken elements. Following Nechad and others (2005), we postulate the following dependence of the damage, $P(e)$, on the deformation, $e$ :

$$
P(e)=1-\left(\frac{e_{01}}{e+e_{02}}\right)^{\xi}
$$

where $e_{01}, e_{02}$ and $\xi$ are constitutive properties of the bond material.

Finally, by combining the previous equations, Faillettaz and others (2010) found a creep model that computes the critical time (i.e. failure of the bond) as a function of the stress experienced by the bond, $s$, given by:

$$
t_{\mathrm{C}}= \begin{cases}\frac{1}{K} \exp (-\gamma s) & \text { if } s>s^{\star} \\ \rightarrow \infty & \text { if } s \leq s^{\star}\end{cases}
$$

where

$$
\gamma=\frac{\beta e_{02}^{\xi}}{e_{01}^{\xi}}
$$

and

$$
s^{\star}=E\left(\frac{e_{01}}{\mu}\right)^{\mu}\left(\frac{\mu-1}{e_{02}}\right)^{\mu-1} .
$$

Creep properties are defined by the parameters $K, \beta, e_{01}, e_{02}$ and $\xi$, that we need to fix for our simulations.

We need to find the most appropriate parameters to describe the creep behavior of ice. The ice of natural glaciers has a complex polycrystalline structure composed of crystals of different sizes. From Equation (7), a fraction, $1-\left(e_{01} / e_{02}\right)^{\xi}$, of all the representative elements present undergo abrupt failure immediately after the stress is applied. Since ice does not show significant damage immediately after being loaded, a reasonable assumption is $e_{01}=e_{02}$. The relative heterogeneity of the material is introduced with the parameter $\xi$. Despite its complex structure, ice is a fairly homogeneous material compared to a fiber matrix composite. The more homogeneous a material, the greater $\xi$. In the following, we set $\xi=10$ which means that ice is not very heterogeneous; e.g. Nechad and others (2005) used $\xi \approx 2$ for a fiber matrix composite. Moreover, as $e_{01}=e_{02}$, it is $\xi$ that influences parameter $s^{\star}$, i.e. the critical stress above which damage starts. The change in $s^{\star}$ values is small compared with that of $\xi$ (e.g. $\xi=2 \Rightarrow s^{\star}=7.5 \times 10^{-4} E$, $\left.\xi=5 \Rightarrow s^{\star}=2.4 \times 10^{-4} E, \xi=10 \Rightarrow s^{\star}=1.4 \times 10^{-4} E\right)$.

The other parameters describing the deformation of the Eyring dashpot under an applied stress are $\beta$ for the nonlinear term and $K$ for the linear term. It is difficult to infer such parameters for ice. Nechad and others (2005) used $\beta=50 \times$ $10^{-9} \mathrm{~Pa}^{-1}$ and $K=10^{5} \mathrm{~s}^{-1}$ for a fiber matrix composite. As ice is significantly weaker, we arbitrarily choose $\beta=$ $10^{-7} \mathrm{~Pa}^{-1}$ and $K=10^{-3} \mathrm{~s}^{-1}$. With a tensile strength of ice of $1 \mathrm{MPa}$, we obtain, from Equation (5), de/dt $=10^{-4} \mathrm{~s}^{-1}$, which is coherent with the behavior of polycrystalline ice (Schulson and Duval, 2009).

\section{NUMERICAL RESULTS}

The aim of the numerical simulations is to test the different causes of the rupture summarized by Röthlisberger (1981) and described in section 2.2. In particular, we intend to provide answers to the following:

What is the influence of glacier geometry on the instability?

Can such a rupture occur without changes of the basal properties? 

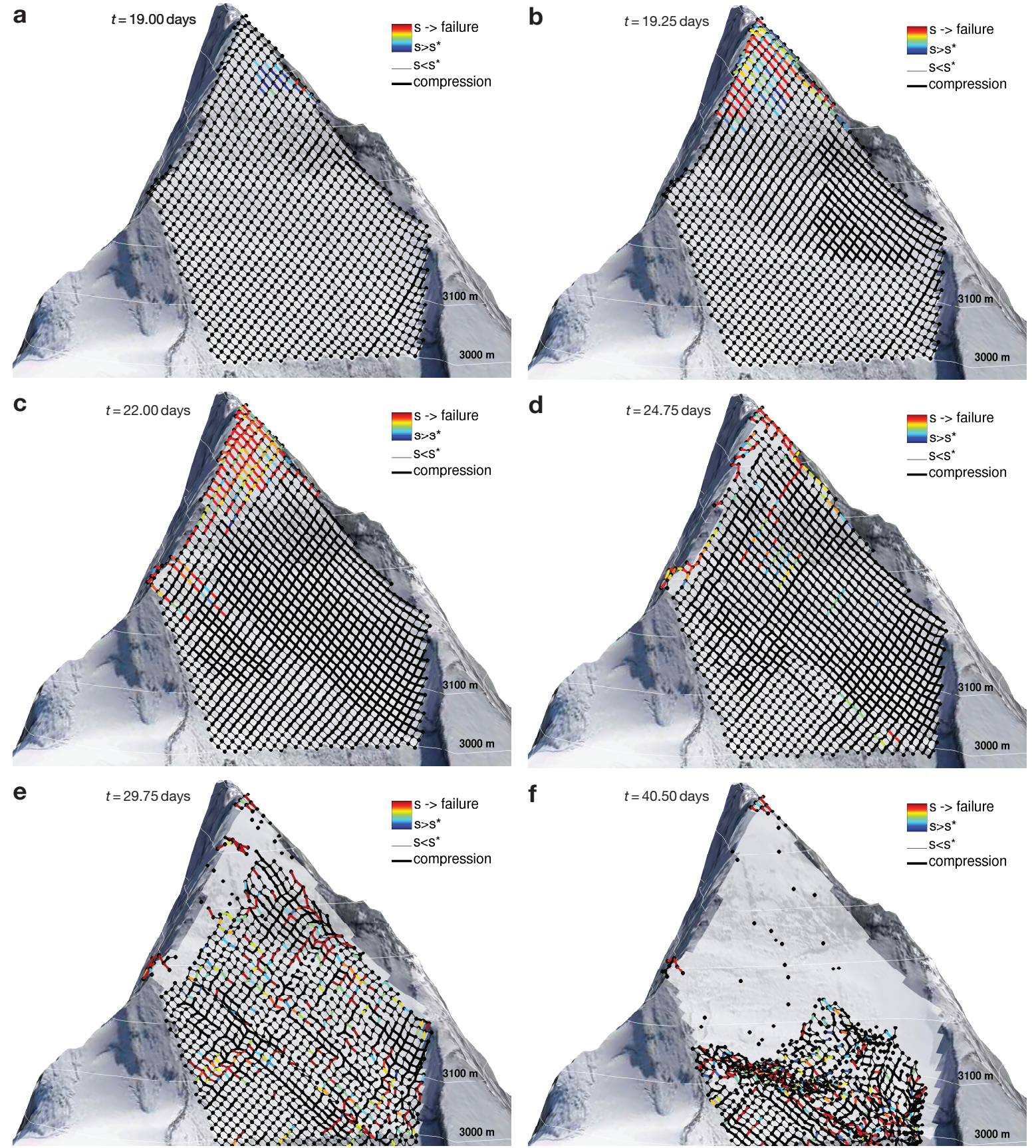

Fig. 11. Six snapshots describing the rupture progression and sliding instability in the block lattice with a constant friction coefficient, $\mu_{0}$, for all blocks, due to an increase of the weight of the blocks (simulating a positive mass balance). The blocks are presented as points at the nodes of the square lattice. The color of each bond indicates the time remaining to rupture: red (close to rupture) to blue (far from rupture). Bonds in compression are drawn as thick black lines. Bonds without unstable tertiary creep damage are represented as thin black lines. Similar results are obtained by progressively decreasing the friction coefficient for all blocks.

How rapidly does the instability develop?

Can we expect some precursors?

\subsection{Description of the simulation}

Blocks are distributed in a regular mesh on the inclined plane, so bonds are initially stress-free. At each time-step we evaluate, for each block, the local bed slope from the DEM of the Altels area (Fig. 10). This aims to mimic the real topography of Altelsgletscher. To determine the causes of the glacier collapse, we test the different contributions described by Röthlisberger (1981) (section 2.2).

Table 1 summarizes the parameters used in our simulations.

\subsection{Qualitative results}

Is the 1895 Altels collapse solely due to glacier thickening?

To answer this question, we tested the case of a constant friction coefficient in the presence of a progressive increase of block weight. This means that mass is added at a constant rate on each block. In all the simulations performed, results show that an instability starts from the upper part of the glacier, in contradiction to the observations (Fig. 11). This could be explained by the bedrock topography; the slope is indeed steeper in the upper part, inducing an initial sliding of the upper blocks. Then this instability propagates downwards and the whole glacier collapses. 
Table 1. Parameters used for the simulation. $n$ is the linear dimension of the lattice of blocks, which has a total of $n \times n$ blocks

\begin{tabular}{lc}
\hline Parameter & Value \\
\hline Geometric parameters & \\
$n$ & 70 \\
$m_{\text {block }}$ & $24.75 \times 10^{6} \mathrm{~kg}$ \\
$\phi$ & $30-45^{\circ}$ \\
Friction parameters & \\
$A$ & 0.1 \\
$\theta_{0}$ & 100 days \\
$\mu_{0}$ & 1 \\
$\dot{\delta} 0$ & $10^{-3} \mathrm{md}^{-1}$ \\
$C r e e p$ parameters & $10^{9} \mathrm{~Pa}$ \\
$E$ & $10^{-7} \mathrm{~Pa}^{-1}$ \\
$\beta$ & $10^{3} \mathrm{~s}$ \\
$C \sim 1 / K$ & 10 \\
$\xi$ & 0.003 \\
$e_{01}$ & 0.003 \\
$e_{02}$ & \\
\hline
\end{tabular}

The progressive thickening is therefore not the cause of the 1895 Altels break-off event.

\section{Is the 1895 Altels break-off due to uniform warming} conditions at the bedrock?

At such altitudes the glacier is expected to be cold, i.e. frozen onto its bedrock. But we saw above that it experienced successive extremely hot summers, which could have initiated the break-off. Warming conditions could lead to a lubrication at the bedrock, due to penetration of meltwater and the consequent increase in basal water pressure. This can cause decoupling of the glacier from its bedrock and a decrease in friction between ice and bedrock. There are two ways to model uniform warming conditions in our model: (1) uniformly decreasing the friction coefficient under each block and (2) decreasing the tangential component of the weight of each block. We tested both approaches, and found very similar qualitative results. Again, as expected, the whole glacier collapses, starting from its upper part (Fig. 11), for the same topographical reasons as explained above.

Differential evolution of the basal properties likely affects the stability of this glacier.

\section{Is the 1895 Altels collapse due to a local decrease in} the friction coefficient?

We now show that the most likely scenario to reproduce the geometry of the observed rupture is to progressively modify the basal properties in a restricted zone, corresponding to the likely temperate area at the bedrock (Röthlisberger, 1981).

In the following, the friction coefficient is decreased at different rates, $\delta \mu / \delta t$, on three different surface areas (Fig. 12), corresponding to the assumed temperate bedrock zone. This simulates water penetrating the glacier and lubricating the ice/bedrock interface.

Figure 13 shows the evolution of the set of blocks in the regime where the instability develops. Different phases can be distinguished during this simulation:

In the following, the value of $\mu_{0}$ is set larger than $\arctan (\max (\phi))$, where $\phi$ is the slope evaluated from the DEM of the glacier bed. In this way, the glacier is assumed to be
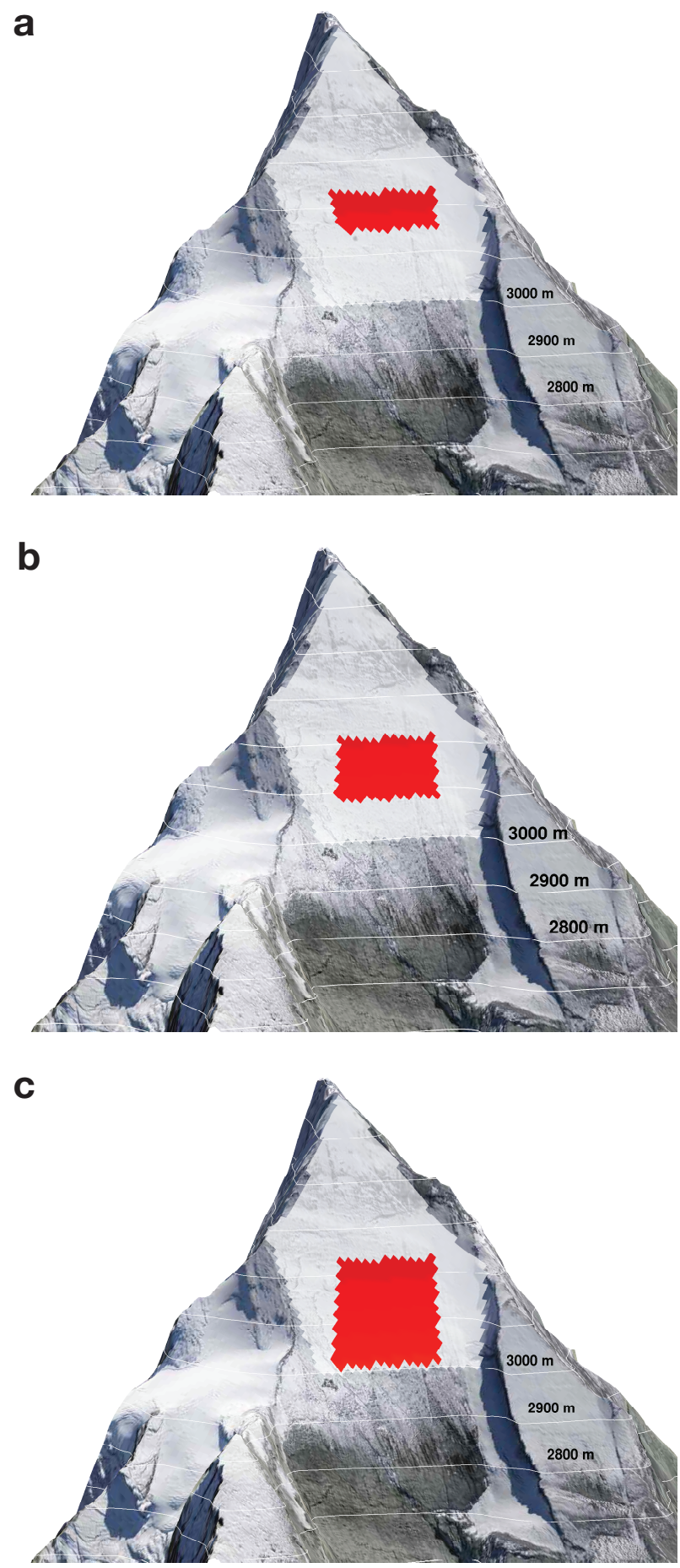

Fig. 12. Zones where the basal friction coefficient is decreased. Their extension was determined according to Röthlisberger (1981) (see Fig. 5).

stable when the simulation starts. At each numerical timestep, the friction coefficient, $\mu_{0}$, is decreased by $\delta \mu / \delta t$.

1. Initially, blocks situated in the zone where the friction coefficient is decreased start sliding where the bedrock slope is largest. Sliding of these blocks leads to a change in stress experienced by the bonds. This internal bond deformation propagates upstream (Fig. 13a).

2. Then the glacier starts accommodating its new stress state, resulting in a quiet phase. The number of sliding blocks progressively increases, leading to stronger interactions 

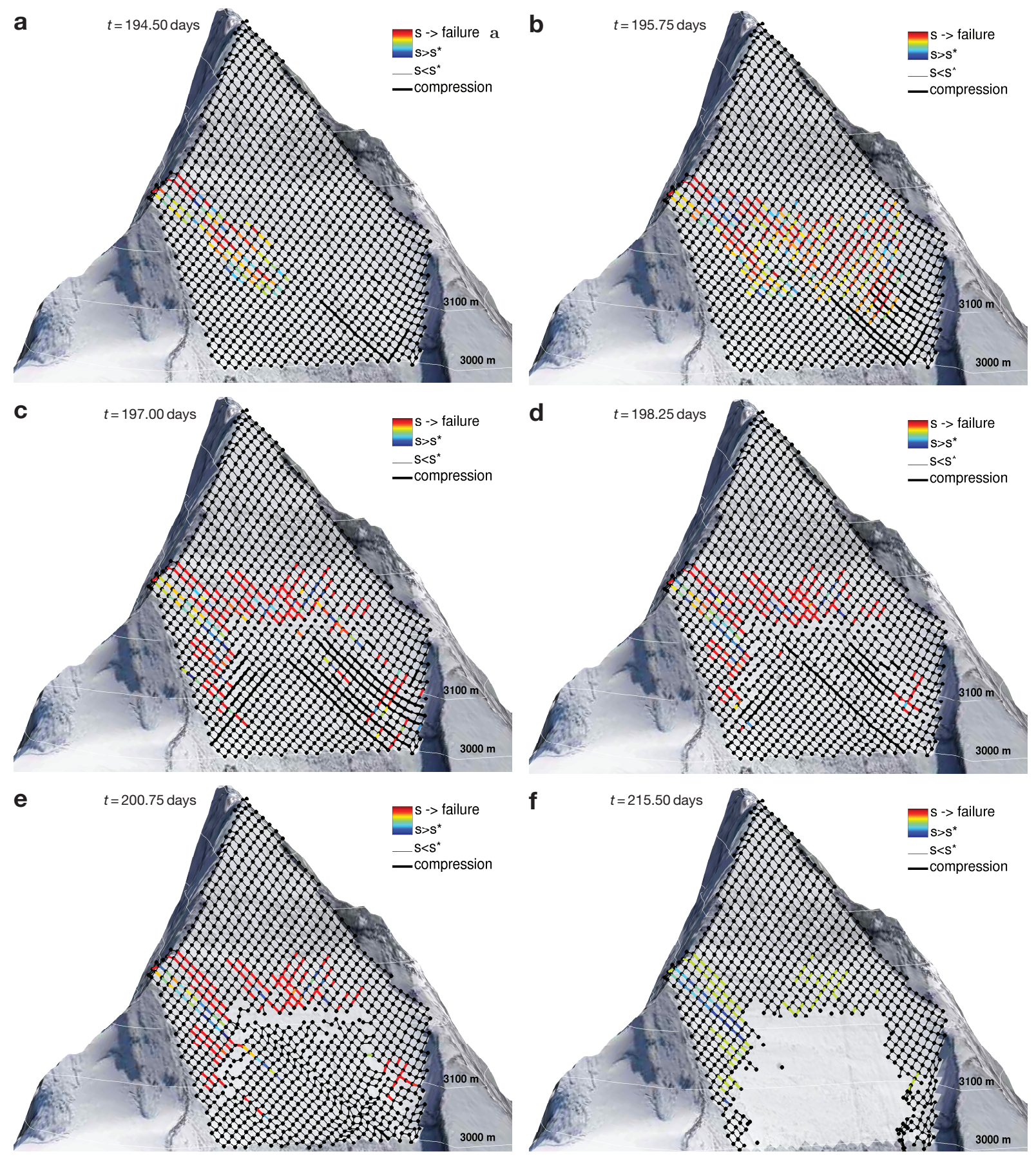

Fig. 13. Six snapshots showing the rupture progression and sliding instability in the block lattice for the largest zone where the basal friction coefficient was progressively reduced. The blocks are presented as points at the nodes of the square lattice. The color of each bond encodes the time remaining to rupture: red (close to rupture) to blue (far from rupture). Bonds in compression are drawn as thick black lines. Bonds without unstable tertiary creep damage are represented as thin black lines.

and to synchronization of the sliding blocks (Fig. 13d and e).

3. After a certain time (depending on $\delta \mu / \delta t$ ) the lattice starts fracturing. A large crack appears perpendicular to the main slope around the middle of the lattice (Fig. 13b and c). This corresponds to the opening of the crevasse just below the bergschrund (Fig. 4b).

4. The final instability develops. The blocks located below the upper crevasse start to accelerate and a fracture of side bonds propagates in the bedrock slope direction, forming an unstable slab, which finally slides off (Fig. 13f).
Initiation of the instability

For each of the three process zones (i.e. the area where the friction coefficient is decreased) and for different rates of decrease of the friction coefficient (RDFCs), $\delta(\mu) / \delta(t)$, we show the number of sliding blocks at each time-step in Figure 14. It appears that, in all cases, the instability evolves rapidly, typically within 1-2 days. Two different regimes can be distinguished: a first quiescent one, in which isolated blocks slide, and a second active one, in which blocks start to slide in clusters, leading to the final collapse.

The number of sliding blocks after the onset of the instability depends on the RDFC. The greater the RDFC, the 

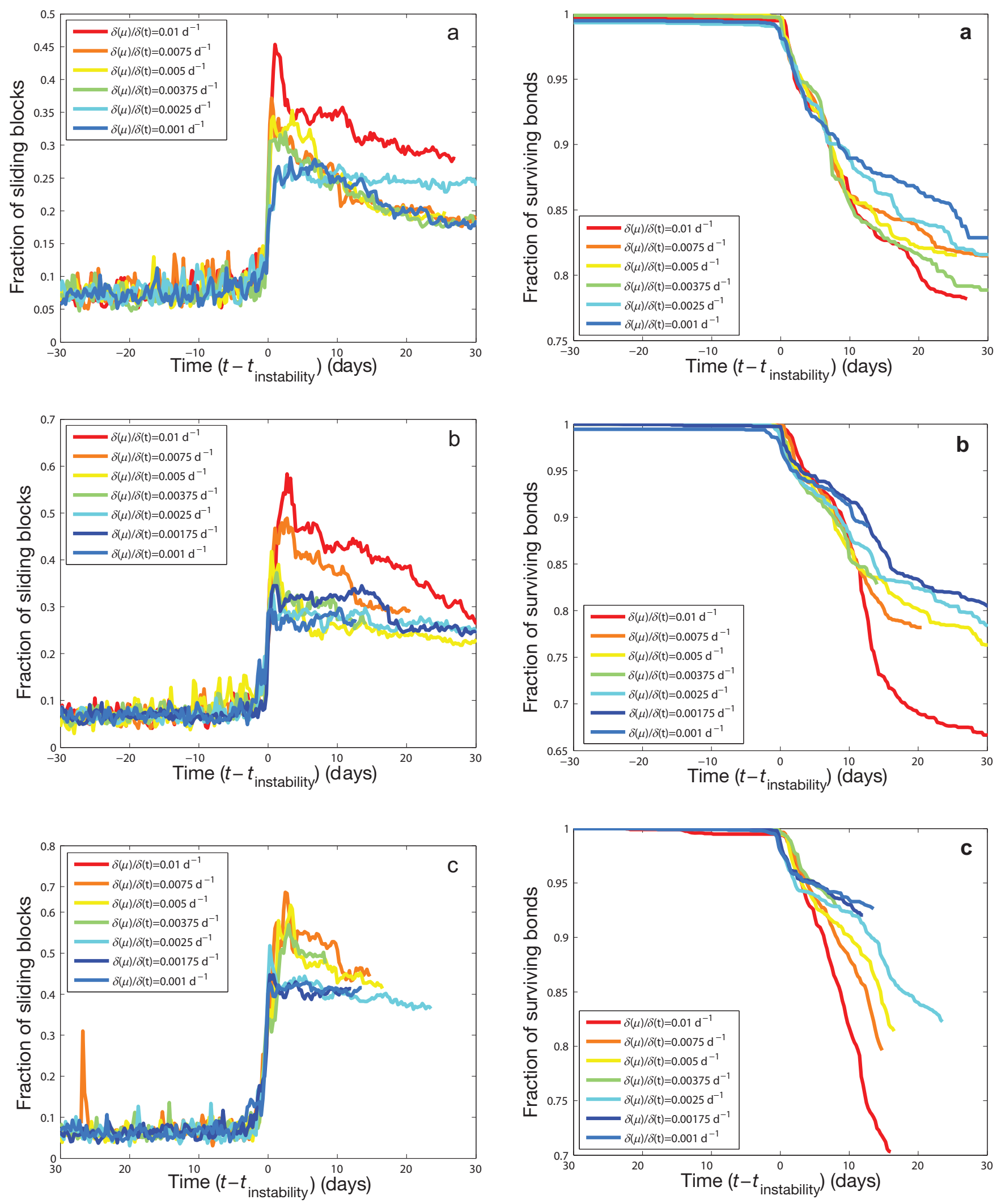

Fig. 14. Fraction of sliding blocks within the glacier for different $\delta \mu / \delta t$ as a function of time, for the three different process zones (minimum, medium and maximum corresponding to Figure $12 \mathrm{a}, \mathrm{b}$ and $\mathrm{c}$, respectively).

larger the number of sliding blocks. When the RDFC is small, the glacier has time to adapt to changes in basal conditions. In this case, the size of the initial unstable cluster is strictly given by the size of the process zone.

Fig. 15. Fraction of the surviving bonds within the glacier for different RDFCs, $\delta \mu / \delta t$, as a function of time, for the three different process zones (minimum, medium and maximum corresponding to Figure. $12 \mathrm{a}, \mathrm{b}$ and c, respectively).

\section{Damage evolution within the glacier}

In order to measure the damage evolution within the glacier, we count the number of surviving bonds during each simulation. Figure 15 shows the number of surviving bonds 

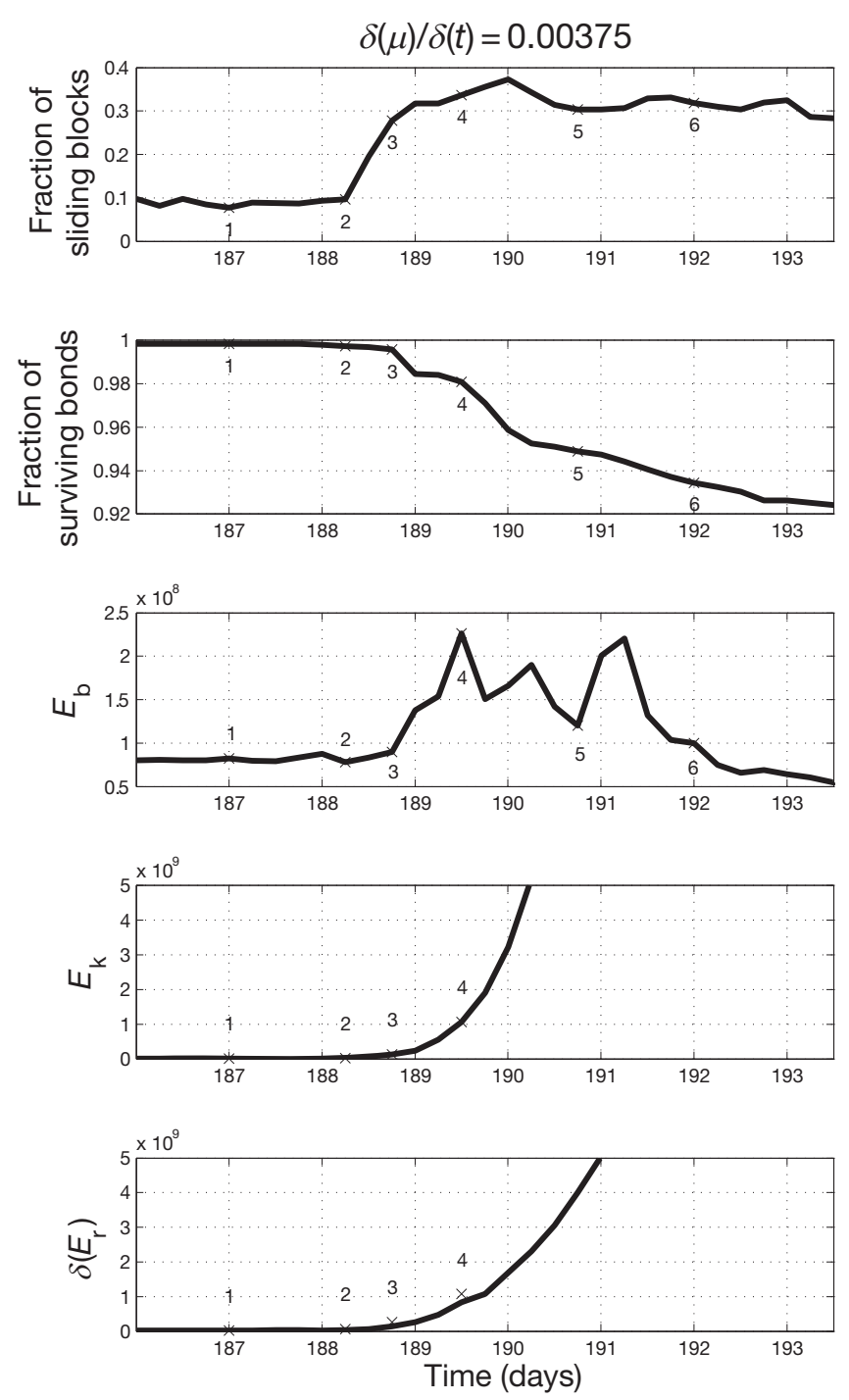

Fig. 16. Evolution of the energy stored in the bonds, $E_{\mathrm{b}}$, of the kinetic energy, $E_{\mathrm{k}}$, and of the radiated energy, $\delta E_{\mathrm{r}}$, during the destabilization process.

within the lattice at each time-step for different process zones and different RDFCs. A rapid increase in the damage a few days after the initiation of the instability can be observed for all simulations. Moreover, this increase does not seem to depend on the RDFC. Results show that, once the behavior enters the active regime, bonds start to fail, leading to the opening of the crown crevasse. That the crevasse opens very rapidly, typically within a few days, was observed by Heim (1895).

\section{Energy analysis}

In order to detect precursors to the rupture, we investigated the evolution of the energy stored in the bonds, the kinetic energy (corresponding to the flow velocity) and the radiated energy (i.e. energy released by the rupture of bonds) during the destabilization process (Fig. 16).

Six phases can be distinguished. (1) The glacier remains in a stable phase. (2) Initiation of the instability. (3) The number of sliding blocks drastically increases. (4) The number of sliding blocks reaches a maximum and the energy stored in the bonds increases. Note that the increase of kinetic and radiated energies starts to be visible. (5) The energy

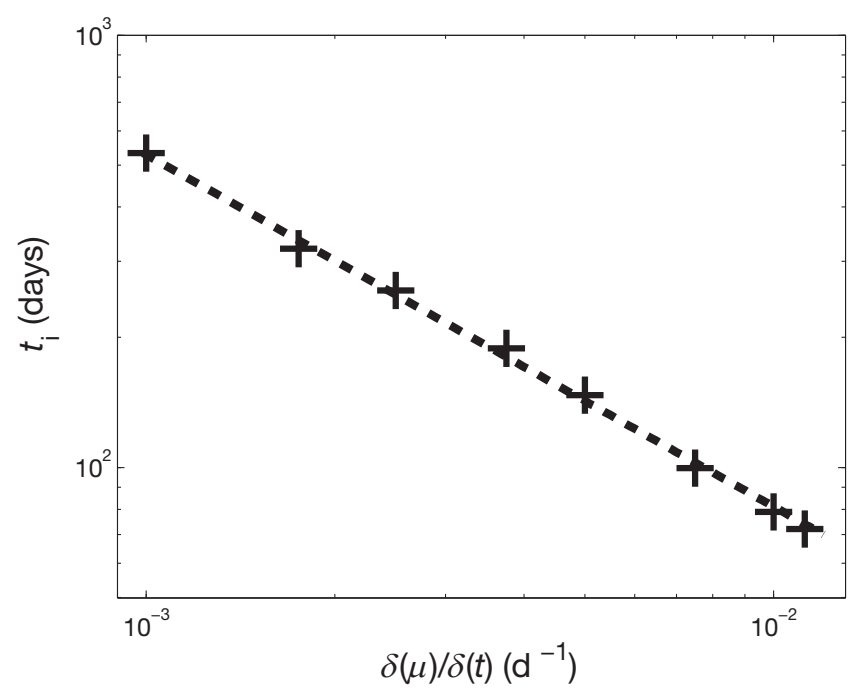

Fig. 17. Time of rupture, $t_{\mathrm{i}}$, as a function of the RDFC, $\delta \mu / \delta t$, for the medium process zone. The dotted line plots the equation: $t_{\mathrm{i}} \sim(\delta \mu / \delta t)^{-0.82}$.

stored in the bonds drops because the crown crevasse opens. The number of sliding blocks remains unchanged and the instability is now established. Both the kinetic and radiated energies increase. (6) After an increase of the energy stored in the bonds, clusters of bonds fail.

These results show that no precursor to the instability can be inferred from the time evolution for the energies considered earlier than a few days before the break-off.

\subsection{Quantitative results}

The results obtained with the spring-block model are summarized in the following.

Occurrence of the instability as a function of $\delta(\mu) / \delta(t)$ To assess whether the RDFC, $\delta(\mu) / \delta(t))$, influences the final time of rupture, we performed independent runs with different rates and evaluated their respective rupture times. The results show that the rupture occurs earlier for greater RDFC, which is not surprising (Fig. 17). However, the time of rupture does not depend linearly on RDFC but follows a power law with an exponent, $b$, of -0.82 . The exponent was estimated using the maximum-likelihood fitting method with goodness-of-fit tests based on the Smirnov test (e.g. Clauset and others, 2009). This means that for small RDFC the glacier has time to adapt to these changes and the final instability arises later than in the case of large RDFC.

The influence of the surface area of the process zone, $S$, on the time of rupture, $t_{i}$, was tested and we found an inverse effect compared with the RDFC. Specifically, a glacier for which a large RDFC acts on a small process zone becomes unstable after the same time as a glacier subjected to a small RDFC applied to a large process zone. This can be summarized by plotting the reduced variable $t_{\mathrm{i}} S^{0.78}$ as a function of $(\delta \mu / \delta t)^{-0.82}$, as shown in Figure 18.

The determination of these two parameters is not yet possible, especially for the area of the process zone. The collapse of three power laws shown in Figure 18 can be rewritten as $t_{\mathrm{i}} \sim[S(\delta \mu / \delta t)]^{-\nu}$, where $\nu \approx 0.8$. This law expresses a combined 'size' effect (through the term $S$ ) and a rate-dependence effect (through the term $\delta \mu / \delta t$ ). Similar behavior is found in most heterogeneous mechanical 
systems going to failure (Collins, 1993; Carpinteri, 1996). Interestingly, the combined dependence of the failure time, $t_{i}$, on the unstable area, $S$, and on the rate, $\delta \mu / \delta t$, is through their product, suggesting that the driving mechanism for the failure time is the total shear force applied to the unstable area.

\section{CONCLUSIONS}

The Altelsgletcher fall of 1895 is the largest known icefall in the Alps. The mechanisms leading to this event are not fully understood. With a new model, developed by Faillettaz and others (2010), of the progressive maturation of a heterogeneous mass towards a gravity-driven instability, characterized by the competition between frictional sliding and tension cracking, we have contributed to a better understanding of this event. We used an array of sliding blocks on an inclined (and curved) basal topography, which interact via elastic-brittle springs. A realistic state- and rate-dependent friction law was used for the block/bed interaction. We modeled the material properties of the mass and its progressive damage eventually leading to failure, by means of a laboratory-based stress corrosion law governing rupture of the springs.

Our simulations show that the only way to reproduce the particular arch shape of the crown crevasse was to reduce the basal friction coefficient in a limited area. Such a breakoff arises because of the onset of a weak zone at the interface between the glacier and its bedrock, probably due to infiltration of meltwater trapped within the glacier. Climatic observations indicate that the air temperature increased during summers in the 3 years before the event, supporting this assumption.

A two-step behavior can be seen from our simulations: (1) a quiescent phase without visible changes with a duration depending on the RDFC, followed by (2) an active regime with a rapid increase of basal motion within a few days before the break-off. As a consequence of the increased basal motion, a crown crevasse opens (as was observed) and the final rupture occurs. This means the destabilization process of a hanging glacier due to progressive warming of the ice/bed interface towards a temperate regime is expected to occur without any visible sign, until a few days prior to the collapse.

The area of the process zone and the RDFC have an equivalent relative influence on the time of onset of the instability. A small process zone area with a large RDFC will lead to the same behavior as a large process zone area with a small RDFC. From a practical point of view, knowledge of both parameters is needed to predict the onset of such an instability. Unfortunately, the a priori determination of these parameters is far from possible, particularly the area of the process zone.

Faillettaz and others (2008, 2011) showed that seismic measurements could help to predict the approaching mechanical instability of cold hanging glaciers with some seismic precursors (e.g. by using changes in the statistical behavior of icequakes). Unfortunately, we could not infer any seismic precursors prior to the instability of Altelsgletscher from our modeling results.

In a more general context, climate change may affect the stability of cold hanging glaciers. Moreover, as the rupture process takes some time to develop and external precursors are only visible a few days prior to the break-off, some cold

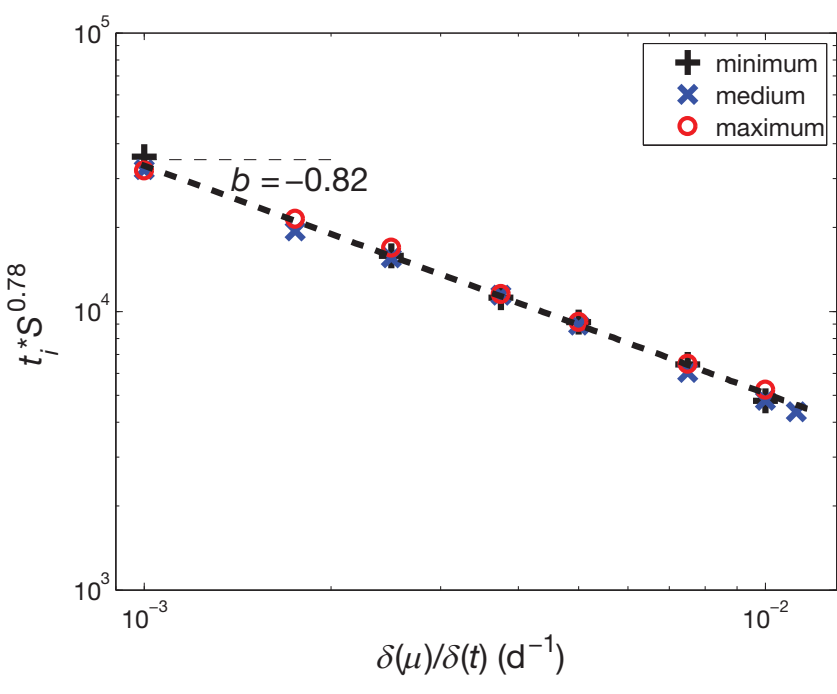

Fig. 18. Time of rupture, $t_{\mathrm{i}}$, as a function of $\delta \mu / \delta t$. The dotted line plots the equation: $t_{\mathrm{i}} S^{0.78} \sim 116(\delta \mu / \delta t)^{-0.82}$.

hanging glaciers could already be in the unstable phase where the instability is developing. Early warning of such events is still far from being possible.

\section{ACKNOWLEDGEMENTS}

Comments by two anonymous reviewers and the editor, T.H. Jacka, substantially contributed to the clarity of the manuscript. This work was partly funded by the European Union seventh framework program's (EU-FP7) project Assessing Climate impacts on the Quantity and quality of WAter (ACQWA; grant 212250).

\section{REFERENCES}

Andersen, J.V., D. Sornette and K.-T. Leung. 1997. Tricritical behavior in rupture induced by disorder. Phys. Rev. Lett., 78(11), 2140-2143.

Barnes, P., D. Tabor and J.C.F. Walker. 1971. The friction and creep of polycrystalline ice. Proc. R. Soc. London, Ser. A, 324(1557), 127-155.

Begert, M., T. Schlegel and W. Kirchhofer. 2005. Homogeneous temperature and precipitation series of Switzerland from 1864 to 2000. Int. J. Climatol., 25(1), 65-80.

Carpinteri, A., ed. 1996. Size-scale effects in the failure mechanisms of materials and structures. London, E \& FN Spon.

Clauset, A., C.R. Shalizi and M.E.J. Newman. 2009. Power-law distributions in empirical data. SIAM Rev., 51(4), 661-703.

Collins, J.A. 1993. Failure of materials in mechanical design: analysis, prediction, prevention. Second edition. New York, Wiley.

Dieterich, J.H. 1994. A constitutive law for rate of earthquake production and its application to earthquake clustering. J. Geophys. Res., 99(B2), 2601-2618.

Du Pasquier, L. 1896. L'avalanche du glacier de l'Altels le 11 septembre 1895. Ann. Géogr., 5(23), 458-468.

Faillettaz, J., A. Pralong, M. Funk and N. Deichmann. 2008. Evidence of log-periodic oscillations and increasing icequake activity during the breaking-off of large ice masses. J. Glaciol., 54(187), 725-737.

Faillettaz, J., D. Sornette and M. Funk. 2010. Gravity-driven instabilities: interplay between state- and velocity-dependent frictional sliding and stress corrosion damage cracking. J. Geophys. Res., 115(B3), B03409. (10.1029/2009JB006512.) 
Faillettaz, J., D. Sornette and M. Funk. 2011. Icequakes coupled with surface displacements for predicting glacier break-off. J. Glaciol., 57(203), 453-460.

Flotron, A. 1977. Movement studies on a hanging glacier in relation with an ice avalanche. J. Glaciol., 19(81), 671-672.

Forel, F.-A. 1895. L'éboulement du Glacier de I'Altels. Arch. Sci. Phys. Natur. [Génèvel, 34, 513-543.

Fortt, A.L. and E.M. Schulson. 2009. Velocity-dependent friction on Coulombic shear faults in ice. Acta Mater., 57(15), 4382-4390.

Heim, A. 1895. Die Gletscherlawine an der Altels am 11 September 1895. In Neujahrsblatt der Zürcherischen Naturforschenden Gesellschaft auf das Jahr 1896. Zürich, Zürcher \& Furrer.

Helmstetter, A., D. Sornette, J.-R. Grasso, J.V. Andersen, S. Gluzman and V. Pisarenko. 2004. Slider-block friction model for landslides: application to Vaiont and La Clapiere landslides. J. Geophys Res., 109(B2), B02409. (10.1029/2002JB002160.)

Hock, R. 2003. Temperature index melt modelling in mountain areas. J. Hydrol., 282(1-4), 104-115.

Hutter, K. 1983. Theoretical glaciology; material science of ice and the mechanics of glaciers and ice sheets. Dordrecht,etc., D. Reidel Publishing Co./Tokyo, Terra Scientific Publishing Co.

Kennedy, F.E., E.M. Schulson and D.E. Jones. 2000. The friction of ice on ice at low sliding velocities. Philos. Mag. A, 80(5), $1093-1110$.

Leung, K.-T. and J.V. Andersen. 1997. Phase transition in a springblock model of surface fracture. Europhys. Lett., 38(8), 589-594.

Lishman, B., P. Sammonds and D. Feltham. 2011. A rate and state friction law for saline ice. J. Geophys. Res., 116(C5), C05011. (10.1029/2010JC006334.)

Maeno, N. and M. Arakawa. 2004. Adhesion shear theory of ice friction at low sliding velocities, combined with ice sintering. J. Appl. Phys., 95(1), 134-139.

Mikumo, T., K.B. Olsen, E. Fukuyama and Y. Yagi. 2003. Stressbreakdown time and slip-weakening distance inferred from slipvelocity functions on earthquake faults. Bull. Seismol. Soc. Am., 93(1), 264-282.

Montagnat, M. and E.M. Schulson. 2003. On friction and surface cracking during sliding of ice on ice. J. Glaciol., 49(166), 391-396.

Nechad, H., A. Helmstetter, R. El Guerjouma and D. Sornette. 2005. Creep ruptures in heterogeneous materials. Phys. Rev. Lett., 94(4), 045501. (10.1103/PhysRevLett.94.045501.)

Ohmura, A. and H. Kawamura. 2007. Rate- and state-dependent friction law and statistical properties of earthquakes. Europhys. Lett., 77(6), 69001. (10.1209/0295-5075/77/69001.)

Petrovich, J.J. 2003. Mechanical properties of ice and snow. J. Mater. Sci., 38(1), 1-6.

Petrenko, V.F. and R.W. Whitworth. 1999. Physics of ice. Oxford, etc., Oxford University Press.

Pralong, A. and M. Funk. 2006. On the instability of avalanching glaciers. J. Glaciol., 52(176), 31-48.

Raymond, M., M. Wegmann and M. Funk. 2003. Inventar gefährlicher Gletscher in der Schweiz. Mitt. VAW/ETH 182.

Röthlisberger, H. 1981. Eislawinen und Ausbrüche von Gletscherseen. In Kasser, P., ed. Gletscher und Klima - glaciers et climat, Jahrbuch der Schweizerischen Naturforschenden Gesellschaft, wissenschaftlicher Teil 1978. Basel, etc., Birkhäuser Verlag, 170-212.

Scholz, C.H. 1998. Earthquakes and friction laws. Nature, 291(6662), 37-42.

Scholz, C.H. 2002. The mechanics of earthquakes and faulting. Second edition. Cambridge, etc., Cambridge University Press.

Schulson, E.M. and P. Duval. 2009. Creep and fracture of ice. Cambridge, etc., Cambridge University Press.

Vaughan, D.G. 1995. Tidal flexure at ice shelf margins. J. Geophys. Res., 100(B4), 6213-6224.

Zhang, W., T. Iwata, K. Irikura, H. Sekiguchi and M. Bouchon. 2003. Heterogeneous distribution of the dynamic source parameters of the 1999 Chi-Chi, Taiwan, earthquake. J. Geophys. Res., 108(B5), 2232. (10.1029/2002JB001889.

\section{APPENDIX}

\section{Initiation of sliding for a single block}

In section 3.3 we described the subcritical sliding process of a given block interacting via state- and velocity-dependent solid friction with its inclined basal surface. When the subcritical sliding velocity, $\mathrm{d} \delta / \mathrm{d} t$, diverges (we refer to the time when this occurs as the 'critical time', $t_{f}$, for the frictional sliding instability), this indicates a change towards a dynamical sliding regime where inertia (the block mass and its acceleration) has to be taken into account.

In this appendix we explicitly calculate how the critical time, $t_{f}$, is obtained and define its dependence on the parameters and boundary conditions. Let us call $T \equiv$ $\left\|\sum \vec{F}_{\text {bond }}-T_{\text {weight }} \vec{x}\right\|$ (or $N \equiv N_{\text {weight }}$ ) the total shear (or normal) force exerted on a given block, where $\vec{F}_{\text {bond }}$ is the force exerted by a neighboring spring bond, and $N_{\text {weight }}$ and $T_{\text {weight }}$ are the normal and tangential forces due to the weight of the block. We then have

$$
\mu=\frac{T}{N}=\tan \phi,
$$

where $\phi$ is the angle of the basal surface supporting the block. Therefore,

$$
\mu_{0}+A \ln \frac{\dot{\delta}}{\dot{\delta}_{0}}+B \ln \frac{\theta}{\theta_{0}}=\tan \phi .
$$

As mentioned in section $3.3, A-B$ is usually very small for a natural material: $A-B \approx \pm 0.02$. For the sake of simplicity, we assume $A=B$. As discussed in section 3.3, this choice is not restrictive as it recovers the two important regimes (Helmstetter and others, 2004). This leads to

$$
\ln \frac{\dot{\delta}}{\dot{\delta_{0}}} \frac{\theta}{\theta_{0}}=\frac{\tan \phi-\mu_{0}}{A},
$$

whose solution is

$$
\dot{\delta} \theta=\dot{\delta}_{0} \theta_{0} \exp \left(\frac{\tan \phi-\mu_{0}}{A}\right) .
$$

Combining Equations (2) and (A4), we obtain

$$
\dot{\theta}=1-\frac{\theta \dot{\delta}}{D_{\mathrm{c}}}=1-\frac{\dot{\delta}_{0} \theta_{0}}{D_{\mathrm{c}}} \exp \left(\frac{\tan \phi-\mu_{0}}{A}\right) .
$$

Integrating

$$
\theta=\theta_{0}+\left[1-\frac{\dot{\delta}_{0} \theta_{0} \exp \left(\frac{\tan \phi-\mu_{0}}{A}\right)}{D_{\mathrm{c}}}\right] t,
$$

and, using Equation (A4), we obtain

$$
\dot{\delta}=\frac{\dot{\delta}_{0} \theta_{0} \exp \left(\frac{\tan \phi-\mu_{0}}{A}\right)}{\theta_{0}+\left[1-\frac{\dot{\delta}_{0} \theta_{0}}{D_{c}} \exp \left(\frac{\tan \phi-\mu_{0}}{A}\right)\right] t} .
$$

This expression exhibits the usual regimes: a finite time singularity is obtained for $\dot{\delta}_{0} \theta_{0} \exp \left(\frac{\tan \phi-\mu_{0}}{A}\right)>D_{\mathrm{c}}$. In this case, Equation (A7) can be rewritten as

$$
\dot{\delta}=\frac{D_{\mathrm{c}} \dot{\delta}_{0} \theta_{0} \exp \left(\frac{\tan \phi-\mu_{0}}{A}\right)}{D_{\mathrm{c}}-\dot{\delta}_{0} \theta_{0} \exp \left(\frac{\tan \phi-\mu_{0}}{A}\right)} \frac{1}{t_{\mathrm{f}}-t}
$$

with

$$
t_{\mathrm{f}}=\frac{D_{\mathrm{c}} \theta_{0}}{D_{\mathrm{c}}-\dot{\delta}_{0} \theta_{0} \exp \left(\frac{\tan \phi-\mu_{0}}{A}\right)} .
$$


We can simplify Equation (A8) using the condition that, for $\mu=\tan \phi=\mu_{0}$, we should have $t_{\mathrm{f}} \rightarrow \infty$. But, when $\mu=\mu_{0}$ then $\exp \left[\left(\mu-\mu_{0}\right) / A\right]=1$ and thus, for the condition $t_{\mathrm{f}} \rightarrow \infty$ to hold, we need

$$
\frac{\dot{\delta}_{0} \theta_{0}}{D_{\mathrm{c}}}=1
$$

The final expression for the critical time, $t_{f}$, signaling the transition from subcritical sliding to dynamical inertial sliding is, for $\mu>\mu_{0}$,

$$
t_{\mathrm{f}}=\frac{\theta_{0}}{\exp \left(\frac{\mu_{\mathrm{s}}-\mu_{0}}{A}\right)-1},
$$

while $t_{\mathrm{f}} \rightarrow \infty$ for $\mu \leq \mu_{0}$. Note that the dependence on $\dot{\delta_{0}}$ has disappeared due to the relation of Equation (A10).

To summarize, a given configuration of blocks and spring tensions determines the value of $T \equiv\left\|\sum \vec{F}_{\text {bond }}-T_{\text {weight }} \vec{x}\right\|$ and $N \equiv N_{\text {weight }}$, and therefore of $\mu$ through Equation (A1). Knowing $\mu$ and given the other material parameters, $\theta_{0}, \mu_{0}$ and $A$, we determine the time, $t_{f}$, for the transition to the dynamical regime for that block via Equation (A11).

\section{General algorithm}

The simulation of the frictional process for each block proceeds as follows:

1. A given configuration of blocks and spring tensions determines the value of $T \equiv\left\|\sum \vec{F}_{\text {bond }}-T_{\text {weight }} \vec{x}\right\|$ and $N \equiv N_{\text {weight }}$ for each block and therefore their solid friction coefficient, $\mu$, corresponds to the ratio $T / N$.

2. Knowing $\mu$ for a given block together with other material parameters $\left(\theta_{0}, \mu_{0}\right.$ and $\left.A\right)$ for that block, the time for the transition to the dynamical sliding regime, $t_{\mathrm{f}}$, is calculated using Equation (3). The value of $t_{\mathrm{f}}$ is the waiting time until the next block starts to slide.

3. When the block undergoes a transition into the dynamical sliding regime at time $t_{f}$, its subsequent dynamics should obey Newton's law.
4. The dynamical slide of the block goes on as long as the velocity of the block remains positive. When its velocity reaches zero, we assume that the block is no longer sliding. To account for the heterogeneity and roughness of the sliding surface, we assume that the state variable, $\theta_{0}$, is reset to a new random value after dynamical sliding stops. This random value is taken to reflect the characteristics of new asperities constituting the fresh surface of contact.

5. After a dynamical slide, the forces exerted by the springs that connect the block to its neighbors are updated, as is the new gravitational force (if the basal surface has a curvature), the new value of $\mu$ is obtained, the time counter for frictional creep is reset to zero, and a new process of slow frictional creep develops over the new waiting time, $t_{f}$, that is, in general, different from the previous one.

In summary, simulation of the damage process leading to bond rupture between blocks proceeds as follows:

1. Given an initial configuration of all the blocks within the network, the elastic forces exerted by all bonds can be calculated from their extension/compression.

2. For each bond $i$ subjected to an initial stress $s_{0}(i)$, we calculate the corresponding critical time, $t_{c, 0}(i)$ at which it would rupture if neither of the two blocks connected to it moved in the meantime. For those bonds where $s_{0}(i) \leq s^{*}$, defined in Equation $(8), t_{c, 0}(i)$ is infinite.

3. Some bonds will eventually fail, modifying the force balance on their blocks and accelerating the transition to the sliding regime, after which the stresses in the bonds connected to the same blocks are modified. 